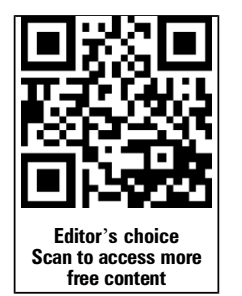

- Additional material is published online only. To view please visit the journal online (http://dx.doi.org/10.1136/ oemed-2014-102722).

${ }^{1}$ School of Medicine, Flinders University, Bedford Park, South Australia, Australia

${ }^{2}$ Department of Rheumatology, Southern Adelaide Local Health Network, Adelaide,

South Australia, Australia

\section{Correspondence to} Dr David G Hancock, School of Medicine, Flinders University, Bedford Park, South Australia 5042, Australia;

hanc0130@flinders.edu.au

Received 20 November 2014 Revised 29 June 2015 Accepted 5 September 2015 Published Online First 24 September 2015

\title{
Wood dust exposure and lung cancer risk: a meta-analysis
}

\author{
David G Hancock, ${ }^{1}$ Mary E Langley, ${ }^{1}$ Kwan Leung Chia, ${ }^{1}$ Richard J Woodman, ${ }^{1}$ \\ E Michael Shanahan ${ }^{1,2}$
}

\section{ABSTRACT}

Occupational lung cancers represent a major health burden due to their increasing prevalence and poor long-term outcomes. While wood dust is a confirmed human carcinogen, its association with lung cancer remains unclear due to inconsistent findings in the literature. We aimed to clarify this association using meta-analysis. We performed a search of 10 databases to identify studies published until June 2014. We assessed the lung cancer risk associated with wood dust exposure as the primary outcome and with wood dustrelated occupations as a secondary outcome. Randomeffects models were used to pool summary risk estimates. 85 publications were included in the metaanalysis. A significantly increased risk for developing lung cancer was observed among studies that directly assessed wood dust exposure (RR 1.21, 95\% Cl 1.05 to $1.39, n=33$ ) and that assessed wood dust-related occupations (RR $1.15,95 \% \mathrm{Cl} 1.07$ to $1.23, n=59$ ). In contrast, a reduced risk for lung cancer was observed among wood dust (RR $0.63,95 \% \mathrm{Cl} 0.39$ to 0.99 , $\mathrm{n}=5$ ) and occupation (RR $0.96,95 \% \mathrm{Cl} 0.95$ to 0.98 , $n=1)$ studies originating in Nordic countries, where softwood dust is the primary exposure. These results were independent of the presence of adjustment for smoking and exposure classification methods. Only minor differences in risk between the histological subtypes were identified. This meta-analysis provides strong evidence for an association between wood dust and lung cancer, which is critically influenced by the geographic region of the study. The reasons for this region-specific effect estimates remain to be clarified, but may suggest a differential effect for hardwood and softwood dusts.

\section{INTRODUCTION}

Occupational lung cancers represent approximately $75 \%$ of all occupational cancers ${ }^{1-4}$ and are a major health burden with relatively poor 5-year survival rates compared with the majority of other cancers. ${ }^{5}{ }^{6}$ Up to $10-20 \%$ of lung cancers have been attributed to occupational exposures ${ }^{1-4}$ and a synergistic effect has been observed between smoking and many of the occupational exposures. ${ }^{1-4}$

Occupational exposure to wood dust remains extremely common in a wide range of jobs, despite advances in occupational health and safety policies. $^{7-10}$ Wood dust was confirmed as a group 1 human carcinogen in 1995 by the International Agency for Research on Cancer (IARC). ${ }^{7}$ However, wood dust has only been conclusively linked to sinonasal cancers, despite individual studies suggesting an association with a range of respiratory and digestive tract cancers. ${ }^{78} 11$ Although the nasal cavity/sinuses appear to be the predominate locations for wood dust deposition, wood processing generally produces a wide variety of particle sizes, at least some of which have been shown to be able to deposit in the lungs. ${ }^{12-16}$ Wood dust has also been confirmed as a respiratory irritant and has been shown to be directly carcinogenic in lung cancer cell lines and to induce lung inflammation in animal models following nasal instillation. ${ }^{17-20}$ While the evidence for lung deposition and direct cellular toxicity provide a plausible biological mechanism for wood dust-induced lung cancer, the relative frequency of deposition in each location may explain the stronger evidence for sinonasal versus lung cancer. ${ }^{7814} 16$

While wood dust exposure has been frequently associated with lung cancer, a confirmed association has not been established by the IARC due to heterogeneous results in the literature. ${ }^{78} \mathrm{~A}$ number of factors have been suggested to contribute to this heterogeneity, including the type of wood dust assessed (hardwood vs softwood), ${ }^{78}$ confounding by smoking ${ }^{1-4}$ and misclassification bias related to the method used for determining dust exposure. ${ }^{21-23}$ While, hardwood dust has been conclusively defined as a human carcinogen, limited evidence exists for softwood dust. ${ }^{7} 8$ However, very few occupational cancer studies have clarified the type of wood dust to which their cohort is exposed making assessment of this variable difficult. Interestingly, the primary wood type varies between countries, and so geographic region may serve as a proxy variable for the type of wood dust assessed in each study. ${ }^{72}$ In particular, wood exposure in Nordic countries is primarily to softwood dust, while hardwood dust exposure is relatively more prevalent in many other countries. ${ }^{7}{ }^{24}$

We performed a systematic review and meta-analysis of the available literature in order to clarify the association between wood dust and lung cancer. We also aimed to assess the influences of geographic region (as a measure of softwood dust exposure), adjustment for smoking and exposure classification methods using subgroup analyses.

\section{METHODS}

\section{Search strategy}

We followed the Preferred Reporting Items for Systematic Reviews and Meta-Analyses (PRISMA) guidelines to conduct our review and analysis. A systematic search of the databases CINAHL (from 1982), EMBASE (from 1974), Google Scholar (from 1980), JSTOR (from 1909), MEDLINE (from 1946), PubMed (from 1946), ScienceDirect 
(from 1856), Web of Science (from 1990) and Wiley Online Library (from 1989) through to June 2014 was completed. The search terms used to search all databases were combinations of Wood Dust ('wood dust', 'sawdust', 'saw dust', 'hardwood dust', 'softwood dust') AND Lung Cancer ('lung cancer', 'lung adenocarcinoma', 'lung carcinoma', 'lung malignancy'). No additional restrictions were used in the search. A systematic search of the Chinese literature in the database CNKI (from 1915) through to June 2014 was also completed. The English search terms were translated into Chinese as: Wood Dust (‘木屑”, ‘鋸木 屑”, ‘軟木屑”, ‘硬木屑”, ‘木鹿”, ‘木粉”, ‘木粉鹿”, ‘軟木粉鹿”, ‘硬 木粉塵”, “木材性粉鹿”) and Lung Cancer ('肺癌”, ‘肺腺癌”, ‘肺’). The Google Scholar, JSTOR, ScienceDirect and CNKI databases perform full-text searches, and thus allow for the identification of studies without 'Lung Cancer' and/or 'Wood Dust' in the abstract.

To identify additional articles that assessed wood dust-related occupations and lung cancer risk, we performed an additional PubMed (from 1946) database search using terms for Wood-Related Occupations (occupation, hardwood, softwood, wood, woodworker, carpenter, furniture, cabinet, joiner, mill, sawmill) AND Cancer (cancer, carcinoma, adenocarcinoma). Cancer was used in the search string in order to identify articles where 'Lung Cancer' was not specifically listed in the abstract.

References in all identified publications, and in the IARC monographs on wood dust, ${ }^{78}$ were also reviewed for additional studies.

\section{Eligibility criteria}

This review included cohort and case-control studies looking at the relationship between wood dust and lung cancer. Papers assessing wood dust directly were chosen as the primary outcome, while studies that assessed wood dust-related occupations were included as a secondary outcome. We included all studies into the meta-analysis that met the following criteria:

1. Contained an estimate of relative risk for lung cancer or data allowing such estimates to be calculated.

2. Contained a risk estimate related to a dichotomous index of exposure (ever vs never) or data allowing such estimates to be calculated.

3a. Contained an explicit analysis of wood dust as an exposure category at an individual not occupational level

\section{OR}

3b. Contained an analysis of a wood dust-related occupation (ie, woodworkers, carpenters and furniture/cabinet makers).

4. Were published in English or Chinese.

\section{Study selection}

All articles identified in the database searches were initially screened for eligibility based on their titles and abstracts, followed by a full-text review of eligible articles. All English language articles were independently screened by two authors (DGH and MEL). Chinese language articles were initially screened for eligibility based on their titles and abstracts by a single author (KLC), while all full-text reviews were discussed by two authors (DGH and KLC). Disagreements between reviewers were resolved by consensus among all authors (DGH, MEL and KLC).

\section{Data extraction}

Data was extracted manually by one author for both the English (DGH) and Chinese (KLC) literature, and was subsequently reviewed by another author (MEL/DGH). Risk estimates for total lung cancer were extracted for the primary analysis, but risk estimates for histological subtypes were also extracted for subanalysis. When multiple methods for defining wood dust exposure were used in a single paper (ie, job-exposure matrix and self-reported), the risk estimate using the exposure classification method presented as the 'gold standard' by the authors of the paper was used. When males and females were analysed separately, the risk estimates for males were included as males represent the majority of those exposed to wood dust.

Publications presenting data on the same cohort of patients were identified by comparing the author lists and study locations. The most recent paper from each cohort was chosen unless a previous paper had a larger cohort size or presented a risk estimate adjusted for more confounding variables. In addition, when a study analysed a subset of the larger population in a cohort, we included the study that used the entire population, even if this was not the most recent study (eg, the full cohort vs the non-smoking subset of the full cohort). The choice of study publication was confirmed by consensus.

Information from each paper was extracted on (1) study design, (2) country of study, (3) sample size, (4) wood dust exposure measure/occupation (5) and measures of effect including 95\% CIs and adjusting/matching variables. Byar's approximation was used to recalculate missing 95\% CIs for cohort studies, while crude ORs were computed for case-control studies without summary effect measures. For data sets in which no events were observed in one of the groups, 0.5 was added to all observations. ${ }^{25}$

\section{Risk of bias in individual studies}

The risk of bias in each study was determined using the Newcastle-Ottawa Scale, which assesses participant selection, comparability and outcome/exposure assessment to a maximum of nine stars. ${ }^{26}$ We rated studies as having low bias (7-9 stars), medium bias (5-6 stars) and high bias (0-4 stars). The risk of bias was determined by two independent authors for English (MEL/DGH) and Chinese (KLC/DGH) publications. Discrepancies in score (generally no more than 1 point) were resolved via consensus.

\section{Statistical analysis}

All statistical analyses were performed using the Metafor package in R. ${ }^{27}$ For each meta-analysis, a random-effects model was specified using the restricted maximum-likelihood estimator method. ${ }^{27}$ Random-effects models were chosen due to the significant heterogeneity in most analyses. For the purposes of pooling risk estimates, ORs were assumed to approximate the true risk ratio, since the baseline risks for lung cancer are generally low. $^{28}$ The primary meta-analysis was performed on all case-control and cohort studies assessing wood dust exposure and lung cancer (not separated into histological subtypes). A priori subgroup analyses were performed based on the geographic region of the study (studies originating outside and inside the Nordic countries (Denmark, Finland, Iceland, Norway, Sweden) as a measure of softwood dust exposure, the method for determining wood dust exposure (job-exposure matrix, self-reported or combination methods) and the use of adjustment for smoking. The Nordic countries were specifically chosen as a proxy variable of softwood dust exposure due to the predominant softwood dust exposure in these countries. $^{72}{ }^{29-31}$ Subanalyses were also performed on all studies that assessed histological subtypes of lung cancer (adenocarcinoma, squamous cell carcinoma, small-cell lung carcinoma or other) and on studies that assessed lung cancer risk among 
wood dust-related occupations (ie, woodworkers, furniture makers, carpenters). Studies directly assessing wood dust exposure and those assessing wood dust-related occupations were analysed separately due to the inherent differences/limitations unique to each study design (ie, different misclassification errors, heterogeneity between occupation definitions and occupation-specific confounders).

The potential for publication bias was determined by assessing funnel plot asymmetry using the Egger regression test. ${ }^{27}$ Asymmetry in a funnel plot (the effect estimates vs their SEs) tests for small study effects (with large SEs), which may suggest publication bias. However, asymmetry can also be due to true biological heterogeneity. ${ }^{32}$ Heterogeneity between studies was assessed using the $\mathrm{I}^{2}$ statistic. Following the Cochrane handbook (http://www.cochrane-handbook.org), $\mathrm{I}^{2}$ values were interpreted as showing moderate (30-60\%), substantial (50-90\%) and considerable (75-100\%) heterogeneity. ${ }^{25}$

\section{RESULTS}

\section{Study characteristics}

Figure 1 details our study selection process. A total of 85 articles were included in the final meta-analysis. ${ }^{5} 30$ 33-115 The included studies are detailed in online supplementary table S1. An additional 56 articles that met the inclusion criteria were identified (see online supplementary table S2), but not used in the meta-analysis as they represented publications on an overlapping cohort of patients, duplicate publications or publications missing information necessary for the meta-analysis. Five additional studies were excluded for presenting data that could not be dichotomised into ever versus never exposure. ${ }^{116-120}$ Forty $\begin{array}{lllllllllllllll}\text { studies }^{5} & 30 & 34-36 & 38 & 40 & 42-44 & 50-54 & 60 & 62 & 64 & 65 & 67 & 69 & 70 & 73-76\end{array}$ 86909193969799100102105106110113115 were rated as having a low risk of bias using the Newcastle-Ottawa Scale (see online supplementary table S1).

\section{Primary meta-analysis on lung cancer and wood dust exposure}

Twenty-four case-control, five nested case-control and nine cohort studies assessing the association between wood dust and lung cancer were included in the primary meta-analysis (figure 2). The studies originated from Belgium, ${ }^{55}$ Canada, ${ }^{42} 6999109$ Chile, ${ }^{59}$ China, ${ }^{48} 6779106111113114$ England, ${ }^{84}$ Finland, ${ }^{30}{ }^{74}$ Holland, $^{76}$ India, ${ }^{63}$ Iran, ${ }^{68}$ Norway, ${ }^{75}$ Pakistan, ${ }^{81}$ Poland, ${ }^{105}$ Russia, ${ }^{34}$ Sweden, ${ }^{72} 86$ Uruguay $^{52}$ and the USA. ${ }^{35} \quad 36 \quad 38-407378 \quad 88102110$ Overall, a significantly increased risk for developing lung cancer following wood dust exposure was observed (RR 1.25, 95\% CI 1.11 to $1.41, \mathrm{n}=38$ ), with 'considerable' heterogeneity between studies $\left(\mathrm{I}^{2}=82.1 \%, \mathrm{p}<0.01\right.$; figure 2$)$.

\section{Subgroup analysis by geographic region of study}

Owing to the well-described predominant softwood exposure in the Nordic countries, ${ }^{7} 24$ the geographic region of each study was used as a measure of the type of wood dust to which that cohort was exposed. In the subgroup analysis of studies originating outside of the Nordic countries (mixed hardwood and softwood dust), there was a significantly increased risk for developing lung cancer associated with wood dust exposure (RR 1.34, 95\% CI 1.19 to $1.50, \mathrm{n}=33)$, with 'moderate' heterogeneity $\left(\mathrm{I}^{2}=39.4 \%\right.$, $\mathrm{p}=0.07$; figure 3 ). In contrast, among studies originating in the Nordic countries (predominantly softwood dust exposure), there was a significantly reduced risk for developing lung cancer (RR $0.63,95 \%$ CI 0.39 to $0.99, \mathrm{n}=5$ ), with 'moderate-substantial' heterogeneity $\left(I^{2}=55.6 \%, p=0.05\right.$; figure 3$)$.

\section{Subgroup analysis of smoking-adjusted studies}

Twenty-three of the wood dust studies controlled for smoking (see online supplementary table S1). The overall association between wood dust and lung cancer incidence was maintained among all studies that controlled for smoking (RR 1.31, 95\% CI 1.10 to $1.56, \mathrm{n}=23$ ). The significantly increased risk for lung cancer was also maintained among studies originating outside the Nordic countries (mixed hardwood and softwood dust) that controlled for smoking (RR 1.48, 95\% CI 1.29 to $1.69, \mathrm{n}=19$, $\left.\mathrm{I}^{2}=0.0 \%\right)$. However, the reduced risk for lung cancer was no longer significant among studies originating within the Nordic countries (predominantly softwood dust exposure) that controlled for smoking (RR $0.64,95 \%$ CI 0.40 to $1.01, \mathrm{n}=4$, $\left.\mathrm{I}^{2}=62.2 \%\right)$.
Figure 1 Flow chart of study selection strategy. * Other sources include the International Agency for Research on Cancer (IARC) monographs and the reference lists of relevant publications. Potentially relevant studies were not counted if they were identified using the database search.

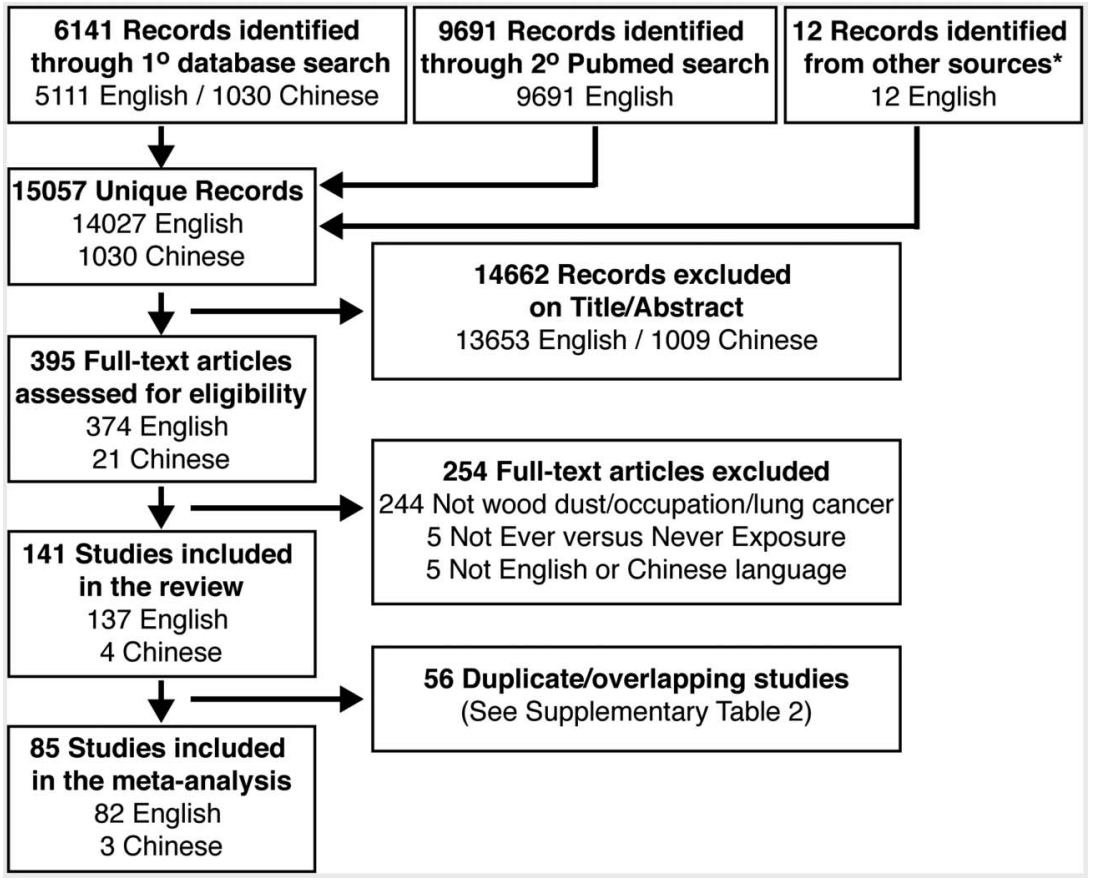




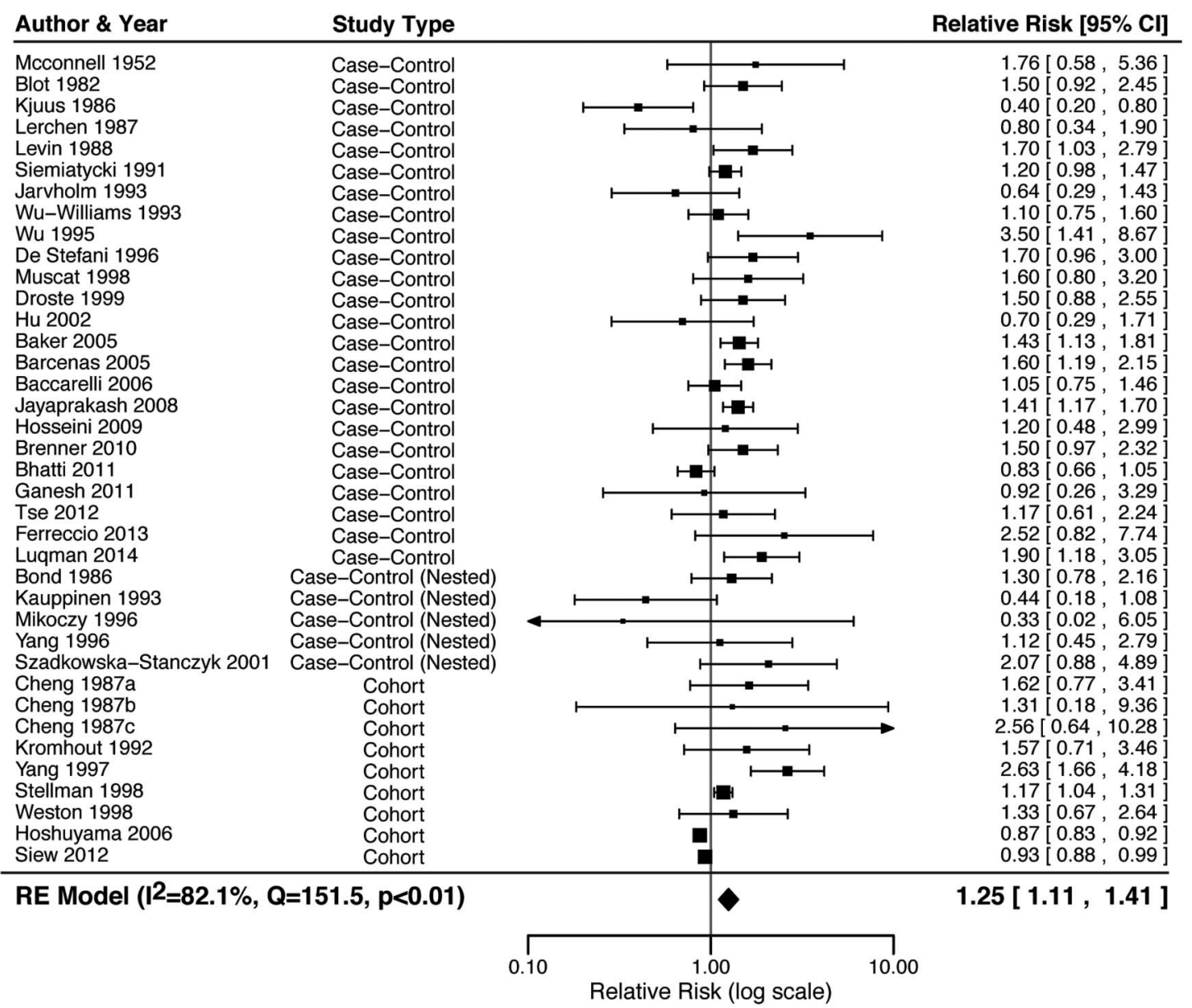

Figure 2 Forest plot of all studies assessing wood dust and lung cancer incidence.

\section{Subgroup analysis on method for classifying wood dust exposure}

Nineteen of the studies used self-reported exposure, 15 studies used a job-exposure matrix, and four studies used a combination of methods to determine wood dust exposure (see online supplementary table S1). Across all studies, a significantly increased risk for lung cancer incidence following wood dust exposure was identified in studies using self-reported exposure (RR 1.29, $95 \%$ CI 1.15 to $\left.1.45, \mathrm{n}=19, \mathrm{I}^{2}=23.5 \%\right)$ or combination methods (RR $1.47,95 \%$ CI 1.11 to $1.96, \mathrm{n}=4, \mathrm{I}^{2}=50.5$ ), but this association failed to reach significance among those studies using a job-exposure matrix (RR $1.18,95 \%$ CI 0.93 to 1.48 , $\left.\mathrm{n}=15, \mathrm{I}^{2}=92.1 \%\right)$. However, a greater proportion of the studies that used a job-exposure matrix did not control for smoking and/or originated in the Nordic countries (where softwood dust is the predominate exposure). When this subgroup analysis was repeated in a post hoc analysis restricted to studies originating outside of the Nordic countries (mixed hardwood and softwood dust exposure) that also controlled for smoking, a significantly increased risk was observed among studies using the selfreported ( $\mathrm{RR} 1.33,95 \%$ CI 1.16 to $1.51, \mathrm{n}=12, \mathrm{I}^{2}=20.0 \%$ ), job-exposure matrix (RR 1.76, 95\% CI 1.29 to $2.42, \mathrm{n}=5$, $\mathrm{I}^{2}=28.9 \%$ ) and/or combination (RR 2.09, 95\% CI 1.01 to 4.34 , $\mathrm{n}=2, \mathrm{I}^{2}=61.3 \%$ ) methods.

\section{Subanalysis of lung cancer histological subtypes}

Ten studies assessed the effect of wood dust exposure on various histological subtypes of lung cancer (see online supplementary table S1). A significantly elevated risk for developing all of the histological subtypes of lung cancer was observed following wood dust exposure (figure 4). The elevated risk ratios were highest for squamous cell carcinomas (RR 1.54, 95\% CI 1.24 to $1.92, \mathrm{n}=4$ ), followed by those for adenocarcinomas (RR $1.32,95 \%$ CI 1.08 to $1.60, \mathrm{n}=7$ ) and small-cell lung carcinomas (RR 1.32, 95\% CI 1.05 to $1.66, \mathrm{n}=7$ ). Similar trends were observed when the analysis was restricted to studies that controlled for smoking.

\section{Subanalysis on lung cancer and wood dust-related occupations}

Fifty-nine studies assessed the association between wood dust-related occupations and lung cancer risk (see online supplementary table S1). Consistent with the wood dust meta-analysis, a significantly increased risk for lung cancer was observed across all studies (RR $1.15,95 \%$ CI 1.07 to $1.23, \mathrm{n}=59$ ), with 'considerable' heterogeneity between studies $\left(\mathrm{I}^{2}=88.8 \%, \mathrm{p}<0.01\right.$; figure 5). This association remained significant when the multiple subcohorts from a single paper were removed $(R R=1.15) .{ }^{33} 58115$ This association was also not dependent on a single occupational group and remained significant when studies assessing 'furniture makers' $(\mathrm{RR}=1.16, \mathrm{n}=55)$ or 'carpenters' $(R R=1.09, n=40)$ were removed in a post hoc analysis. Finally, this association was also not dependent on the study type, as the association remained significant when case-control (RR 1.17, n=34) and cohort (RR 1.12, $n=26)$ studies were analysed separately.

A significantly increased risk for lung cancer (RR 1.15, 95\% CI 1.07 to $1.24, \mathrm{n}=58$ ) was observed among the studies 


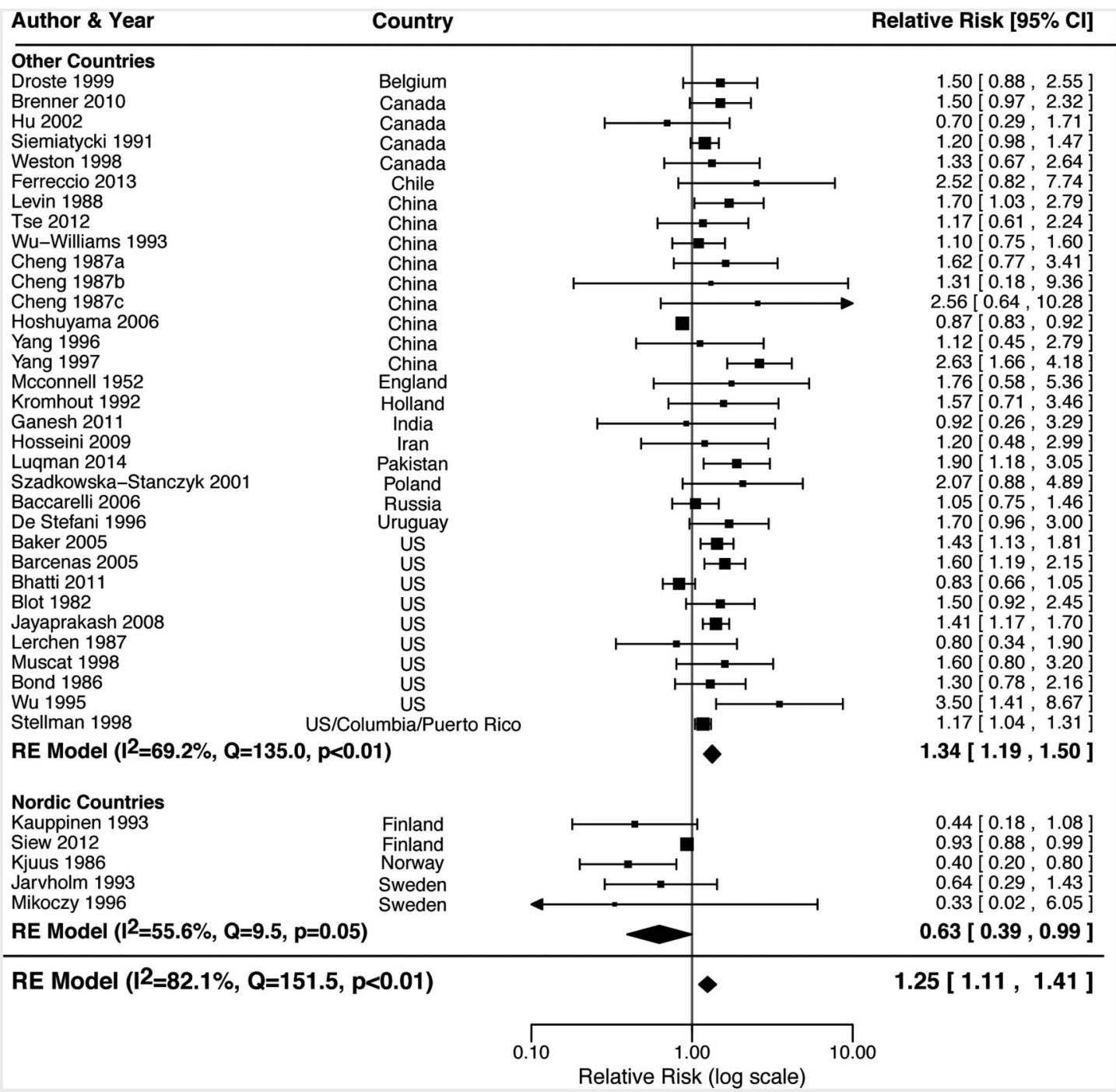

Figure 3 Forest plot all studies assessing wood dust and lung cancer incidence, subdivided based on the geographic region of study origin.

originating outside the Nordic countries, while a significantly reduced risk for lung cancer (RR 0.96, 95\% CI 0.95 to 0.98) was observed in the one included study ${ }^{5}$ that originated in the Nordic countries (predominantly softwood dust exposure; figure 5).

\section{Publication bias}

No evidence for publication bias was observed on visual inspection of funnel plot asymmetry across all wood dust studies (see online supplementary figure S1A) and there was no evidence using Egger's test for small study bias $(p=0.456)$. There was some suggestion of funnel plot asymmetry across the wood dust-related occupational studies (see online supplementary figure S1B), although this failed to reach significance using Egger's test for small study bias $(p=0.080)$.

\section{DISCUSSION}

Occupational exposure to wood dust was confirmed to be carcinogenic to humans (group 1) by the IARC in 1994, but the evidence as a risk factor for lung cancer has been inconsistent. ${ }^{7}$ The recent IARC monograph Volume 100C also failed to confirm an association between lung cancer and wood dust due to the heterogeneous findings in the literature. ${ }^{8} 11$ Our robust literature search and meta-analysis showed a significantly elevated risk for developing lung cancer following wood dust exposure when pooling all studies (figure 2). We also observed this significantly elevated risk in studies that assessed lung cancer risk among wood dust-related occupations, and not wood dust exposure per se (figure 5). Importantly, evidence for wood dust deposition in the lungs and its in vitro carcinogenicity provide a biological mechanism to support the observed elevated risk for lung cancer. ${ }^{7} 814 \quad 16$ The results of this meta-analysis were maintained when studies that had not controlled for smoking were excluded. Smoking is the strongest risk factor for lung cancer, and confounding due to cigarette smoking often limits the accurate assessment of the effects of other lung carcinogens. ${ }^{14}$

We had initially hypothesised that studies originating from the Nordic countries would show a proportionally lower risk for lung cancer due to the predominant softwood dust exposure in these countries ${ }^{7} 24^{29-31}$ and the limited evidence supporting the carcinogenicity of softwood dust. ${ }^{7} 8$ In support of this hypothesis, we observed a significantly elevated risk for developing lung cancer among studies originating outside of the Nordic countries and a significantly decreased risk among studies originating from the Nordic countries (figures 3 and 5). Furthermore, the only two wood dust studies in this meta-analysis that specified the type of dust to which their 


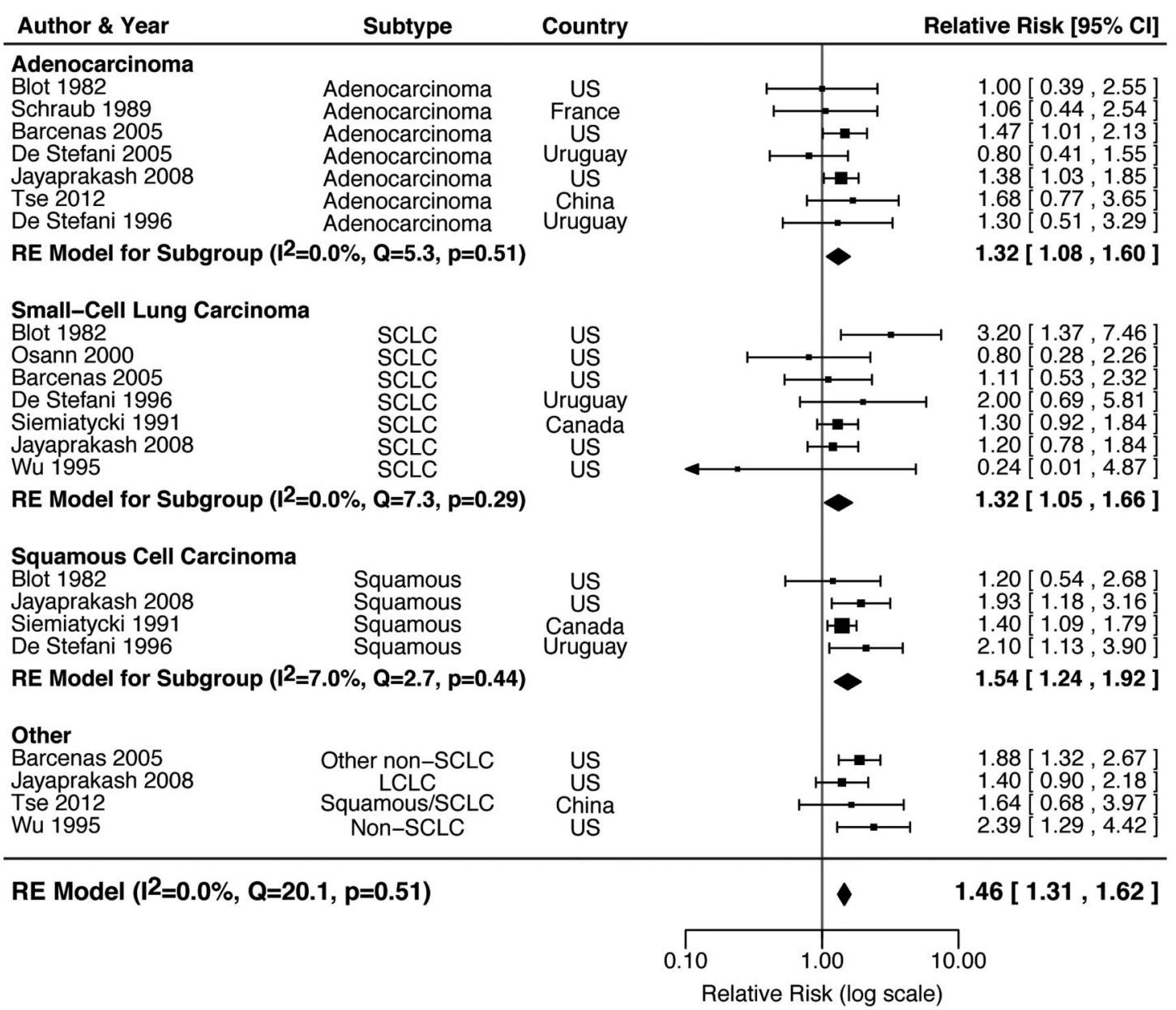

Figure 4 Forest plot of all studies assessing wood dust and histological subtypes of lung cancer, subdivided based on histological subtype. SCLC, small-cell lung carcinoma; LCLC, large-cell lung carcinoma.

cohort was exposed independently concluded that their identification of a decreased risk was due to the predominant softwood dust exposure in their cohorts. ${ }^{30} 38$ However, one of these studies originated in the USA ${ }^{38}$ indicating that wood dust type rather than region is the likely cause of the differential risk effects of hardwood and softwood dusts on lung cancer. Consistent with these findings, all studies assessing wood dust-related occupations that described predominant exposure to softwood dust also showed a decreased or non-significant risk for lung cancer, independent of their origin in the Nordic countries. $^{5} 3896101$

While we used the geographic region of the study population as a measure for the type of wood dust exposure, there are a number of other potential explanations that may contribute to the region-specific trends observed in this meta-analysis. This includes unidentified confounders, ${ }^{2} 331$ genetics ${ }^{7} 8121122$ and/ or differences in occupational health and safety standards between countries. $^{2} 5$ 123-126 A potential confounder for the decreased risk for lung cancer with wood dust exposure is bacterial endotoxins, arising from bacterial colonisation of either stored wood or loose wood dust. ${ }^{31} 38127$ Bacterial endotoxin is thought to protect against lung cancer, ${ }^{127}$ and thus increased exposure to this bacterial contamination among wood workers compared with the general population may help explain the reduced risk estimates for lung cancer in the Nordic countries. $^{31} 38$ The contrasting risk estimates may also be due to region-specific differences in genetics, environment or health policies, which might reduce the size of any increased risk. Nordic countries are generally thought to be world leaders in occupational health and safety practice, especially at the time when majority of these studies were conducted. ${ }^{5} 123124$ The lack of any increased risk among the Nordic countries may therefore be due to differences in the wood dust-exposed workers, such as exposure to relatively lower levels of wood dust or other harmful exposures as a result of better occupational health and safety practice. ${ }^{2} 125126$

One of the most commonly cited limitations of the observational studies on wood dust exposure is the potential for measurement bias in the exposure assessment. ${ }^{22} 76$ Self-reported exposure strategies are generally susceptible to recall bias, while job-exposure matrix strategies can be susceptible to variations in true exposure under a given job title. ${ }^{22}{ }^{76}$ However, an increased risk for lung cancer was observed across all methods of determining wood dust exposure, especially after controlling for geographic region and smoking. This finding was supported by three studies that directly compared the exposure methods and showed no significant differences between methods. ${ }^{36} 5576$

We also assessed the association between wood dust exposure and the different histological subtypes of lung cancer (figure 4). We observed significantly increased risk estimates for all histological subtypes of lung cancer, with the highest risk for squamous cell carcinomas (although CIs largely overlapped). This appears to contradict data on sinonasal cancers, where adenocarcinomas have been most frequently observed among 


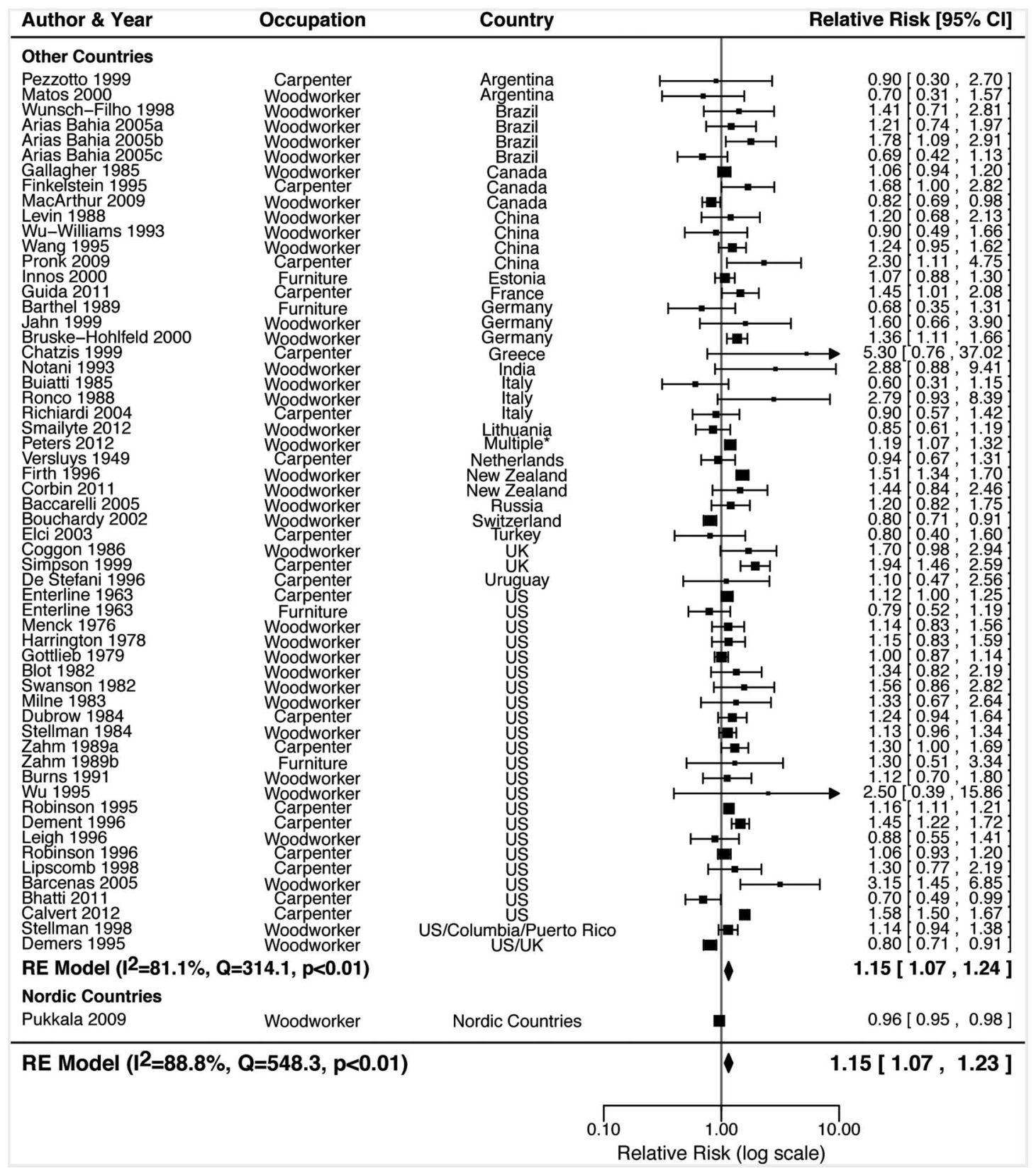

Figure 5 Forest plot all studies assessing wood dust-related occupations and lung cancer incidence, subdivided based on the geographic region of study origin.

woodworkers, ${ }^{7} 8$ although some studies have identified squamous cell carcinomas more commonly. ${ }^{30} 128$ Overall, these data suggest that wood dust increases the risk for all subtypes of lung cancer, and not only a specific subtype.

To the best of our knowledge, this is the first systematic review or meta-analysis assessing wood dust and lung cancer risk, outside of the IARC publications. ${ }^{7} 8$ We performed a robust search of the English and Chinese literature and identified a large number of studies not included in the IARC publications. Our analysis also included a large number of studies where wood dust and lung cancer was not the primary outcome of the paper, thereby reducing the likelihood of publication bias of positive results, which was supported by our assessment of funnel plot asymmetry. However, it is also possible that studies assessing a large number of exposures would provide a less accurate assessment of true wood dust exposure, although we found no evidence to support this hypothesis.
In the current meta-analysis, we chose to primarily focus on studies that specifically assessed wood dust exposure in order to provide the most direct assessment of the relationship between wood dust exposure and lung cancer risk. We also aimed to avoid some of the inherent challenges/limitations of assessing purely occupation-based studies, including the heterogeneity in occupational classifications and the greater risk for individual occupation-specific factors obscuring any wood dust-specific effects. $^{25} 103129130$ Consistent with this, some of the studies showed a large degree of variation in the individual risk estimates when multiple different wood dust-related occupations analysed within the same paper (not shown). ${ }^{45} 103$ However, the observation of a significantly elevated risk for lung cancer (of similar magnitude) among these occupation-based studies (figure 5) adds further weight to the association between wood dust and lung cancer, and also suggests that our focus on wood dust-specific studies did not bias the results of this meta-analysis. 
There are a number of potential limitations to our meta-analysis. First, we were unable to perform any analyses to assess the dose-response relationship between wood dust and lung cancer or to determine any effects related to duration of exposure. These factors were generally not assessed or assessed using a variety of approaches making a quantitative synthesis unfeasible. Second, the included studies varied greatly in their study design/population characteristics and accounting for all these factors in our meta-analysis was not feasible. Finally, unknown confounding exposures might still explain our findings. Asbestos, silica, formaldehyde, solvents and exhausts are all associated with wood dust-related professions and have been independently linked with lung cancer. ${ }^{3}{ }^{7} 8$ However, the studies included in this meta-analysis analysed wood dust exposure from a diverse range of occupational contexts, thereby limiting the possibility that a single confounding exposure accounted for the observed associations.

In conclusion, this meta-analysis has demonstrated significant associations between lung cancer and wood dust exposure or employment in wood dust-related occupations, with an increased risk among studies that originated outside of the Nordic countries (mixed hardwood and softwood dust exposure). The reduced risk for lung cancer observed following wood dust exposure in Nordic countries may be due to the predominant softwood dust exposure in these countries. Larger studies designed to explore the causes of these differing associations are needed.

Contributors DGH was involved in study design and supervision, analysis and interpretation of data, statistical analysis, and drafting of the manuscript. MEL and $\mathrm{KLC}$ were involved in analysis and interpretation of data, and critical revision of the manuscript. RJW was involved in statistical analysis and critical revision of the manuscript. EMS was involved in drafting of the manuscript and critical revision of the manuscript.

Competing interests None declared.

Provenance and peer review Not commissioned; externally peer reviewed.

\section{REFERENCES}

1 Field RW, Withers BL. Occupational and environmental causes of lung cancer. Clin Chest Med 2012;33:681-703.

2 Franceschi S, Wild CP. Meeting the global demands of epidemiologic transitionthe indispensable role of cancer prevention. Mol Oncol 2013;7:1-13.

3 Freund A. Listing occupational carcinogens. Environ Health Perspect 2005;113: A152.

4 Spyratos D, Zarogoulidis $\mathrm{P}$, Porpodis $\mathrm{K}$, et al. Occupational exposure and lung cancer. J Thorac Dis 2013;5(Suppl 4):S440-5.

5 Pukkala E, Martinsen Jl, Lynge E, et al. Occupation and cancer-follow-up of 15 million people in five Nordic countries. Acta Oncol 2009;48:646-790.

6 Rushton L, Hutchings SJ, Fortunato L, et al. Occupational cancer burden in Great Britain. Br J Cancer 2012;107(Suppl 1):S3-7.

7 IARC Working Group on the Evaluation of Carcinogenic Risks to Humans. Wood dust and formaldehyde. World Health Organization, International Agency for Research on Cancer, 1995.

8 IARC Working Group on the Evaluation of Carcinogenic Risks to Humans. Wood dust: a review of human carcinogens: arsenic, metals, fibres, and dusts. World Health Organization, International Agency for Research on Cancer, 2012.

9 Labreche F, Duguay P, Ostiguy C, et al. Estimating occupational exposure to carcinogens in Quebec. Am J Ind Med 2013;56:1040-50.

10 Ruano-Ravina A, Garcia-Lavandeira JA, Torres-Duran M, et al. Leisure time activities related to carcinogen exposure and lung cancer risk in never smokers. A case-control study. Environ Res 2014;132C:33-7.

11 Straif $\mathrm{K}$, Benbrahim-Tallaa L, Baan R, et al. A review of human carcinogens-part C: metals, arsenic, dusts, and fibres. Lancet Oncol 2009;10:453-4.

12 Andersen $\mathrm{HC}$, Andersen I, Solgaard J. Nasal cancers, symptoms and upper airway function in woodworkers. Br J Ind Med 1977;34:201-7.

13 Brown JS, Gordon T, Price 0, et al. Thoracic and respirable particle definitions for human health risk assessment. Part Fibre Toxicol 2013;10:12

14 Nylander LA, Dement JM. Carcinogenic effects of wood dust: review and discussion. Am J Ind Med 1993;24:619-47.
15 Oberdorster G, Oberdorster E, Oberdorster J. Nanotoxicology: an emerging discipline evolving from studies of ultrafine particles. Environ Health Perspect 2005;113:823-39.

16 Demers PA, Teschke K, Kennedy SM. What to do about softwood? A review of respiratory effects and recommendations regarding exposure limits. Am J Ind Med 1997:31:385-98.

17 Bornholdt J, Saber AT, Sharma AK, et al. Inflammatory response and genotoxicity of seven wood dusts in the human epithelial cell line A549. Mutat Res 2007;632:78-88.

18 Maatta J, Lehto $\mathrm{M}$, Leino $\mathrm{M}$, et al. Mechanisms of particle-induced pulmonary inflammation in a mouse model: exposure to wood dust. Toxicol Sci 2006:93:96-104.

19 Maatta J, Luukkonen R, Husgafvel-Pursiainen K, et al. Comparison of hardwood and softwood dust-induced expression of cytokines and chemokines in mouse macrophage RAW 264.7 cells. Toxicology 2006;218:13-21.

20 Perez-Rios M, Ruano-Ravina A, Etminan M, et al. A meta-analysis on wood dust exposure and risk of asthma. Allergy 2010;65:467-73.

21 Bourgkard E, Wild P, Gonzalez M, et al. Comparison of exposure assessment methods in a lung cancer case-control study: performance of a lifelong task-based questionnaire for asbestos and PAHs. Occup Environ Med 2013;70:884-91.

22 Fritschi L, Siemiatycki J, Richardson L. Self-assessed versus expert-assessed occupational exposures. Am J Epidemiol 1996;144:521-7.

23 Hardt JS, Vermeulen R, Peters $S$, et al. A comparison of exposure assessment approaches: lung cancer and occupational asbestos exposure in a population-based case-control study. Occup Environ Med 2014;71: 282-8.

24 Andersen A, Barlow L, Engeland A, et al. Work-related cancer in the Nordic countries. Scand I Work Environ Health 1999;25(Suppl 2):1-116.

25 Higgins JP, Green S, Collaboration C. Cochrane handbook for systematic reviews of interventions version 5.0.2 [updated September 2009]. Cochrane Collaboration, 2009.

26 Wells G, Shea B, O'Connell D, et al. The Newcastle-Ottawa Scale (NOS) for assessing the quality of non randomised studies in meta-analyses. Secondary the Newcastle-Ottawa Scale (NOS) for assessing the quality of non randomised studies in meta-analyses. 2014. http://www.ohri.ca/programs/clinicalepidemiology/oxford.asp

27 Viechtbauer W. Conducting meta-analyses in R with the metafor package. J Stat Software 2010;36:1-48.

28 Grant RL. Converting an odds ratio to a range of plausible relative risks for better communication of research findings. BMJ 2014;348:f7450.

29 Laakkonen A, Kyyronen P, Kauppinen T, et al. Occupational exposure to eight organic dusts and respiratory cancer among Finns. Occup Environ Med 2006;63:726-33.

30 Siew SS, Kauppinen T, Kyyronen $\mathrm{P}$, et al. Occupational exposure to wood dust and formaldehyde and risk of nasal, nasopharyngeal, and lung cancer among Finnish men. Cancer Manag Res 2012;4:223-32.

31 Rushton L. Organic dusts and respiratory cancer: a complex issue. Occup Environ Med 2006;63:717.

32 Sterne JA, Sutton AJ, loannidis JP, et al. Recommendations for examining and interpreting funnel plot asymmetry in meta-analyses of randomised controlled trials. BMJ 2011;343:d4002.

33 Arias Bahia SH, Echenique Mattos I, Koifman S. Cancer and wood-related occupational exposure in the Amazon region of Brazil. Environ Res 2005:99:132-40.

34 Baccarelli A, Khmelnitskii O, Tretiakova M, et al. Risk of lung cancer from exposure to dusts and fibers in Leningrad Province, Russia. Am I Ind Med 2006:49:460-7.

35 Baker JA, McCann SE, Reid ME, et al. Associations between black tea and coffee consumption and risk of lung cancer among current and former smokers. Nutr Cancer 2005;52:15-21.

36 Barcenas $\mathrm{CH}$, Delclos $\mathrm{GL}$, El-Zein $\mathrm{R}$, et al. Wood dust exposure and the association with lung cancer risk. Am J Ind Med 2005;47:349-57.

37 Barthel E, Dietrich M. Retrospective cohort study of cancer morbidity in furniture makers exposed to wood dust. Z Gesamte Hyg 1989;35:279-81.

38 Bhatti P, Newcomer L, Onstad L, et al. Wood dust exposure and risk of lung cancer. Occup Environ Med 2011;68:599-604.

39 Blot WJ, Davies JE, Brown LM, et al. Occupation and the high risk of lung cancer in Northeast Florida. Cancer 1982;50:364-71.

40 Bond GG, Flores GH, Shellenberger RJ, et al. Nested case-control study of lung cancer among chemical workers. Am J Epidemiol 1986;124:53-66.

41 Bouchardy C, Schuler G, Minder C, et al. Cancer risk by occupation and socioeconomic group among men-a study by the Association of Swiss Cancer Registries. Scand I Work Environ Health 2002;28(Suppl 1):1-88.

42 Brenner DR, Hung RJ, Tsao MS, et al. Lung cancer risk in never-smokers: a population-based case-control study of epidemiologic risk factors. BMC Cancer 2010;10:285.

43 Bruske-Hohlfeld I, Mohner M, Pohlabeln H, et al. Occupational lung cancer risk for men in Germany: results from a pooled case-control study. Am J Epidemiol 2000;151:384-95. 
44 Buiatti E, Kriebel D, Geddes M, et al. A case control study of lung cancer in Florence, Italy. I. Occupational risk factors. J Epidemiol Community Health 1985;39:244-50.

45 Burns PB, Swanson GM. The Occupational Cancer Incidence Surveillance Study (OCISS): risk of lung cancer by usual occupation and industry in the Detroit metropolitan area. Am J Ind Med 1991;19:655-71.

46 Calvert GM, Luckhaupt S, Lee SJ, et al. Lung cancer risk among construction workers in California, 1988-2007. Am J Ind Med 2012;55:412-22.

47 Chatzis C, Danaka G, Linos A, et al. Lung cancer and occupational risk factors in Greece. J Occup Environ Med 1999;41:29-35.

48 Cheng W, Zuo H, Hao Z. [Cancer mortality among woodworkers in Tianjin]. Chin J Ind Hyg Occup Dis 1987;5:22-5.

49 Coggon D, Pannett B, Osmond C, et al. A survey of cancer and occupation in young and middle aged men. I. Cancers of the respiratory tract. $\mathrm{Br} J$ Ind Med 1986;43:332-8.

50 Corbin M, McLean D, Mannetje A, et al. Lung cancer and occupation: a New Zealand cancer registry-based case-control study. Am J Ind Med 2011;54:89-101.

51 De Stefani E, Boffetta P, Brennan P, et al. Occupational exposures and risk of adenocarcinoma of the lung in Uruguay. Cancer Causes Control 2005;16:851-6.

52 De Stefani E, Kogevinas M, Boffetta P, et al. Occupation and the risk of lung cancer in Uruguay. Scand J Work Environ Health 1996;22:346-52.

53 Dement J, Pompeii L, Lipkus IM, et al. Cancer incidence among union carpenters in New Jersey. J Occup Environ Med 2003;45:1059-67.

54 Demers PA, Boffetta P, Kogevinas $M$, et al. Pooled reanalysis of cancer mortality among five cohorts of workers in wood-related industries. Scand J Work Environ Health 1995;21:179-90.

55 Droste JH, Weyler JJ, Van Meerbeeck JP, et al. Occupational risk factors of lung cancer: a hospital based case-control study. Occup Environ Med 1999;56:322-7.

56 Dubrow R, Wegman DH. Cancer and occupation in Massachusetts: a death certificate study. Am J Ind Med 1984;6:207-30.

57 Elci OC, Akpinar-Elci M, Alavanja M, et al. Occupation and the risk of lung cancer by histologic types and morphologic distribution: a case control study in Turkey. Monaldi Arch Chest Dis 2003;59:183-8.

58 Enterline PEPD, McKiever MFBA. Differential mortality from lung cancer by Occupation. J Occup Med 1963;5:283-90.

59 Ferreccio C, Yuan Y, Calle J, et al. Arsenic, tobacco smoke, and occupation: associations of multiple agents with lung and bladder cancer. Epidemiology 2013;24:898-905.

60 Finkelstein MM. Occupational associations with lung cancer in two Ontario cities. Am J Ind Med 1995;27:127-36.

61 Firth HM, Cooke KR, Herbison GP. Male cancer incidence by occupation: New Zealand, 1972-1984. Int J Epidemiol 1996;25:14-21.

62 Gallagher RP, Threlfall WJ, Band PR, et al. Cancer mortality experience of woodworkers, loggers, fishermen, farmers, and miners in British Columbia. Natl Cancer Inst Monogr 1985;69:163-7.

63 Ganesh B, Sushama S, Monika S, et al. A case-control study of risk factors for lung cancer in Mumbai, India. Asian Pac J Cancer Prev 2011;12:357-62.

64 Gottlieb MS, Pickle LW, Blot WJ, et al. Lung cancer in Louisiana: death certificate analysis. J Natl Cancer Inst 1979;63:1131-7.

65 Guida F, Papadopoulos A, Menvielle G, et al. Risk of lung cancer and occupational history: results of a French population-based case-control study, the ICARE study. J Occup Environ Med 2011;53:1068-77.

66 Harrington JM, Blot WJ, Hoover RN, et al. Lung cancer in coastal Georgia: a death certificate analysis of occupation: brief communication. J Natl Cancer Inst 1978:60:295-8.

67 Hoshuyama T, Pan G, Tanaka C, et al. Mortality of iron-steel workers in Anshan, China: a retrospective cohort study. Int J Occup Environ Health 2006;12:193-202.

68 Hosseini M, Naghan PA, Karimi S, et al. Environmental risk factors for lung cancer in Iran: a case-control study. Int J Epidemiol 2009;38:989-96.

$69 \mathrm{Hu}$ J, Mao Y, Dryer D, et al. Canadian Cancer Registries Epidemiology Research Group. Risk factors for lung cancer among Canadian women who have never smoked. Cancer Detect Prev 2002;26:129-38.

70 Innos K, Rahu M, Rahu K, et al. Wood dust exposure and cancer incidence: a retrospective cohort study of furniture workers in Estonia. Am J Ind Med 2000;37:501-11.

71 Jahn I, Ahrens W, Bruske-Hohlfeld I, et al. Occupational risk factors for lung cancer in women: results of a case-control study in Germany. Am J Ind Med 1999:36:90-100.

72 Jarvholm B, Larsson S, Hagberg S, et al. Quantitative importance of asbestos as a cause of lung cancer in a Swedish industrial city: a case-referent study. Eur Respir J 1993;6:1271-5.

73 Jayaprakash V, Natarajan KK, Moysich KB, et al. Wood dust exposure and the risk of upper aero-digestive and respiratory cancers in males. Occup Environ Med 2008;65:647-54.

74 Kauppinen TP, Partanen TJ, Hernberg SG, et al. Chemical exposures and respiratory cancer among Finnish woodworkers. Br J Ind Med 1993;50:143-8.

75 Kjuus $\mathrm{H}$, Skjaerven $\mathrm{R}$, Langard $\mathrm{S}$, et al. A case-referent study of lung cancer, occupational exposures and smoking. I. Comparison of title-based and exposure-based occupational information. Scand J Work Environ Health 1986;12:193-202.

76 Kromhout $H$, Heederik D, Dalderup LM, et al. Performance of two general job-exposure matrices in a study of lung cancer morbidity in the Zutphen cohort. Am J Epidemiol 1992;136:698-711.

77 Leigh JP. Occupations, cigarette smoking, and lung cancer in the epidemiologica follow-up to the NHANES I and the California Occupational Mortality Study. Bull NY Acad Med 1996;73:370-97.

78 Lerchen ML, Wiggins CL, Samet JM. Lung cancer and occupation in New Mexico. J Natl Cancer Inst 1987;79:639-45.

79 Levin LI, Zheng W, Blot WJ, et al. Occupation and lung cancer in Shanghai: a case-control study. Br J Ind Med 1988;45:450-8.

80 Lipscomb HJ, Dement JM. Respiratory diseases among union carpenters: cohort and case-control analyses. Am J Ind Med 1998;33:131-50.

81 Luqman M, Javed MM, Daud S, et al. Risk factors for lung cancer in the Pakistani population. Asian Pac J Cancer Prev 2014;15:3035-9.

82 MacArthur AC, Le ND, Fang $R$, et al. Identification of occupational cancer risk in British Columbia: a population-based case-control study of 2,998 lung cancers by histopathological subtype. Am J Ind Med 2009;52:221-32.

83 Matos EL, Vilensky M, Mirabelli D, et al. Occupational exposures and lung cancer in Buenos Aires, Argentina. J Occup Environ Med 2000;42:653-9.

84 McConnell RB, Gordon KC, Jones T. Occupational and personal factors in the aetiology of carcinoma of the lung. Lancet 1952;2:651-6.

85 Menck HR, Henderson BE. Occupational differences in rates of lung cancer. J Occup Med 1976;18:797-801

86 Mikoczy Z, Schutz A, Stromberg U, et al. Cancer incidence and specific occupational exposures in the Swedish leather tanning industry: a cohort based case-control study. Occup Environ Med 1996;53:463-7.

87 Milne KL, Sandler DP, Everson RB, et al. Lung cancer and occupation in Alameda County: a death certificate case-control study. Am J Ind Med 1983;4:565-75.

88 Muscat JE, Stellman SD, Richie JP Jr, et al. Lung cancer risk and workplace exposures in black men and women. Environ Res 1998:76:78-84.

89 Notani PN, Shah P, Jayant K, et al. Occupation and cancers of the lung and bladder: a case-control study in Bombay. Int J Epidemiol 1993;22:185-91.

90 Osann KE, Lowery JT, Schell MJ. Small cell lung cancer in women: risk associated with smoking, prior respiratory disease, and occupation. Lung Cancer 2000;28:1-10

91 Peters $\mathrm{S}$, Kromhout $\mathrm{H}$, Olsson $\mathrm{AC}$, et al. Occupational exposure to organic dust increases lung cancer risk in the general population. Thorax 2012;67:111-16.

92 Pezzotto SM, Poletto L. Occupation and histopathology of lung cancer: a case-control study in Rosario, Argentina. Am J Ind Med 1999;36:437-43.

93 Pronk A, Coble J, Ji BT, et al. Occupational risk of lung cancer among lifetime non-smoking women in Shanghai, China. Occup Environ Med 2009;66: 672-8.

94 Richiardi L, Boffetta P, Simonato L, et al. Occupational risk factors for lung cancer in men and women: a population-based case-control study in Italy. Cancer Causes Control 2004;15:285-94.

95 Robinson C, Stern F, Halperin W, et al. Assessment of mortality in the construction industry in the United States, 1984-1986. Am J Ind Med 1995;28:49-70.

96 Robinson CF, Petersen M, Sieber WK, et al. Mortality of Carpenters' Union members employed in the U.S. construction or wood products industries, 19871990. Am J Ind Med 1996;30:674-94.

97 Ronco G, Ciccone G, Mirabelli D, et al. Occupation and lung cancer in two industrialized areas of northern Italy. Int J Cancer 1988;41:354-8.

98 Schraub S, Belon-Leneutre M, Mercier M, et al. Adenocarcinoma and wood. Am J Epidemiol 1989;130:1164-6.

99 Siemiatycki J. Risk factors for cancer in the workplace. Boca Raton: CRC Press, 1991.

100 Simpson J, Roman E, Law G, et al. Women's occupation and cancer: preliminary analysis of cancer registrations in England and Wales, 1971-1990. Am J Ind Med 1999;36:172-85.

101 Smailyte G. Cancer incidence among workers exposed to softwood dust in Lithuania. Occup Environ Med 2012;69:449-51.

102 Stellman SD, Demers PA, Colin D, et al. Cancer mortality and wood dust exposure among participants in the American Cancer Society Cancer Prevention Study-II (CPS-II). Am J Ind Med 1998;34:229-37.

103 Stellman SD, Garfinkel L. Cancer mortality among woodworkers. Am J Ind Med 1984:5:343-57.

104 Swanson GM, Belle SH. Cancer morbidity among woodworkers in the U.S. automotive industry. J Occup Med 1982:24:315-19.

105 Szadkowska-Stanczyk I, Szymczak W. Nested case-control study of lung cancer among pulp and paper workers in relation to exposure to dusts. Am J Ind Med 2001:39:547-56.

106 Tse LA, Yu IT, Qiu H, et al. Occupational risks and lung cancer burden for Chinese men: a population-based case-referent study. Cancer Causes Control 2012;23:121-31.

107 Versluys JJ. Cancer and occupation in the Netherlands. Br J Cancer 1949;3:161-85. 
108 Wang QS, Boffetta P, Parkin DM, et al. Occupational risk factors for lung cancer in Tianjin, China. Am J Ind Med 1995;28:353-62.

109 Weston TL. Application of a job exposure matrix to assess cancer mortality risk in a cohort of working men. Queen's University at Kingston, 1998.

110 Wu X, Delclos GL, Annegers JF, et al. A case-control study of wood dust exposure, mutagen sensitivity, and lung cancer risk. Cancer Epidemiol Biomarkers Prev 1995;4:583-8.

111 Wu-Williams $A H, X u Z Y, B l o t$ WJ, et al. Occupation and lung cancer risk among women in northern China. Am J Ind Med 1993;24:67-79.

112 Wunsch-Filho V, Moncau JE, Mirabelli D, et al. Occupational risk factors of lung cancer in Sao Paulo, Brazil. Scand J Work Environ Health 1998;24:118-24.

113 Yang $Y$, Wang M, Wang $Z$, et al. [A retrospective cohort study between wood dust and cancer]. Chin J Ind Med 1996;9:5-9.

114 Yang $Y$, Wang $M$, Wang $Z$, et al. [A cohort study on lung cancer and exposure to wood dust]. Chin I Ind Hyg Occup Dis 1997;15:277-81.

115 Zahm SH, Brownson RC, Chang JC, et al. Study of lung cancer histologic types, occupation, and smoking in Missouri. Am J Ind Med 1989;15:565-78.

116 Bovenzi M, Stanta G, Antiga G, et al. Occupational exposure and lung cancer risk in a coastal area of northeastern Italy. Int Arch Occup Environ Health 1993;65:35-41.

117 Damber LA, Larsson LG. Occupation and male lung cancer: a case-control study in northern Sweden. Br J Ind Med 1987;44:446-53.

118 Goldberg M, Goldberg P, Leclerc A, et al. A 10-year incidence survey of respiratory cancer and a case-control study within a cohort of nickel mining and refining workers in New Caledonia. Cancer Causes Control 1994;5:15-25.

119 Preller L, Balder HF, Tielemans E, et al. Occupational lung cancer risk among men in the Netherlands. Occup Environ Med 2008;65:249-54.
120 Williams RR, Stegens NL, Goldsmith JR. Associations of cancer site and type with occupation and industry from the Third National Cancer Survey Interview. J Nat/ Cancer Inst 1977;59:1147-85.

121 Ridge CA, McErlean AM, Ginsberg MS. Epidemiology of lung cancer. Semin Intervent Radiol 2013;30:93-8.

122 Yang IA, Holloway JW, Fong KM. Genetic susceptibility to lung cancer and co-morbidities. J Thorac Dis 2013;5(Suppl 5):S454-62.

123 Gustavsen B. Work Organization and the 'Scandinavian Model'. Econ Ind Democracy 2007;28:650-71.

124 Suikkanen A, Kunnari M. Principles and concepts in Nordic occupational safety and health policies: dimensions of strategic thinking and approaches. Copenhagen: Nordic Council of Ministers, 2009.

$125 \mathrm{Li} \mathrm{CY}$, Sung FC. A review of the healthy worker effect in occupational epidemiology. Occup Med (Lond) 1999;49:225-9.

126 Shah D. Healthy worker effect phenomenon. Indian J Occup Environ Med 2009;13:77-9.

127 Gioffre A, Marramao A, lanno A. Airborne microorganisms, endotoxin, and dust concentration in wood factories in Italy. Ann Occup Hyg 2012;56: 161-9.

128 Kuijpens JH, Louwman MW, Peters R, et al. Trends in sinonasal cancer in The Netherlands: more squamous cell cancer, less adenocarcinoma.

A population-based study 1973-2009. Eur J Cancer 2012;48:2369-74.

129 Hayes RB, Gerin M, Raatgever JW, et al. Wood-related occupations, wood dust exposure, and sinonasal cancer. Am J Epidemiol 1986;124:569-77.

130 Luce D, Leclerc A, Morcet JF, et al. Occupational risk factors for sinonasal cancer: a case-control study in France. Am J Ind Med 1992;21:163-75. 